\title{
Gambaran Perkembangan Komunikasi Anak Cornelia de Lange Syndrome (CdLS)
}

\author{
Tri Retno Indah Susanti ${ }^{1}$, Meira Erawati ${ }^{1}$, Dwi Retno Nurniningsih ${ }^{2}$
}

${ }^{1}$ Fakultas Kedokteran, Universitas Diponegoro Semarang

${ }^{2}$ RSUP Kariadi Semarang

\begin{tabular}{|c|c|}
\hline Artikel Info & Abstrak \\
\hline $\begin{array}{l}\text { Accepted } \\
23 \text { Mei } 2019\end{array}$ & $\begin{array}{l}\text { Cornelia de Lange Syndrome (CdLS) adalah gangguan perkembangan multisistem yang dikaitkan } \\
\text { dengan gangguan kognitif, malformasi dan gangguan wajah internal yang khas. Gangguan } \\
\text { perkembangan yang terjadi pada Cornelia de Lange Syndrome (CdLS) adalah keterampilan berbahasa } \\
\text { dan berbicara. Tujuan dari penelitian ini adalah melihat peningkatan perkembangan komunikasi anak } \\
\text { Sindrom Cornelia de Lange (CdLS) setelah diberi intervensi play therapy dan terapi wicaradengan } \\
\text { menggunakan media gambar dan warna. Metodologi penelitian ini menggunakan desain studi kasus. } \\
\text { Alat yang digunakan untuk mengukur kemampuan bahasa menggunakan DENVER II. Berdasarkan } \\
\text { hasil penelitian pada } 9 \text { November } 2018 \text {, anak berusia } 3 \text { tahun, } 9 \text { bulan, } 3 \text { hari dengan diagnosis medis } \\
\text { Sindrom Cornelia de Lange (CdLS) dengan keluhan anak belum bisa bicara. Hasil pemeriksaan fisik } \\
\text { menunjukkan terdapat bentuk khas yaitu alis mata menyatu ditengah, bulu mata panjang, terdapat juga } \\
\text { kriteria minor. Hasil pemeriksaan DENVER II dari bahasa, anak masih seperti anak usia } 18 \text { bulan. } \\
\text { Berdasarkan hasil evaluasi setelah } 1 \text { bulan tindakan keperawatan dan kolaborasi dengan terapis, telah } \\
\text { terjadi peningkatan komunikasi anak. } \\
\text { Kata kunci: Cornelia de Lang Syndrome, Peningkatan perkembangan, terapi wicara. }\end{array}$ \\
\hline
\end{tabular}

Description of Communication Development in Children with Cornelia De Lange Syndrome

(Cdls)

Abstract

Cornelia de Lange Syndrome (CdLS) is a multisystem developmental disorder that is associated with cognitive impairments, malformations and internal and typical facial disorders. Developmental disorders that occur in Cornelia de Lange Syndrome (CdLS) are language skills and speech. The purpose of this study was to see the speed of communication development of children of Cornelia de Lange Syndrome (CdLS), after being given an intervention. Improve conversation by using play therapy using image and color media. The methodology of this research uses case study design. The tool used to measure the ability language use the DENVER II. Based on the results of the study on November 9, 2018, children aged 3 years, 9 months, 3 days with a medical diagnosis of Cornelia de Lange Syndrome (CdLS) were obtained with a comparison of children unable to speak. From the results of physical examination, there are typical forms, namely spies in the middle, long eyelashes, also there are minor criteria. The results of DENVER II examination of various children's languages are still like 18 months old children. Based on the evaluation results after 1 month of nursing actions and collaboration with the therapist, there has been an increase in communication of children with Cornelia de Lange Syndrome (CdLS).

Key words: Cornelia de Lang Syndrome, Increased development, Speech therapy

Corresponding author:

Tri Retno Indah Susanti retnot86@gmail.com Jurnal Ilmu Keperawatan Anak, Vol 2 No 1, Mei 2019 DOI: http://dx.doi.org/10.32584/jika.2.1.2019.27-34 e-ISSN 2621-296X 


\section{PENDAHULUAN}

Pertumbuhan dan perkembangan pada bayi atau anak sangat perlu diperhatikan sejak masa konsepsi, karena apabila terjadi kelainan akan sangat mempengaruhi pertumbuhan dan perkembangan individu tersebut di masa depan (Soetiningsih, 2016). Dewasa ini banyak kita temui kelainan kongenital pada bayi, kelainan kongenital itu sendiri adalah kelainan dalam pertumbuhan janin yang terjadi sejak konsepsi dan selama dalam kandungan. Diperkirakan 10-20\% dari kematian janin dalam kandungan dan kematian neonatal disebabkan oleh kelainan kongenital. Khusunya pada bayi berat badan lahir rendah diperkirakan $20 \%$ diantaranya meninggal karena kelainan kongenital dalam minggu pertama kehidupannya (Maryanti \& Kusumawati, 2015)

Anak luar biasa atau anak berkebutuhan khusus adalah anak yang menyimpang dari anak normal yang sebaya, baik dalam bidang intelegensi, fisik, emosi maupun ciri-ciri sosialnya, sehingga mereka memerlukan pelayanan secara khusus (Bahri, 2010). Salah satu anak yang termasuk dalam golongan berkebutuhan khusus adalah anak dengan Cornelia de Lange Syndrome (CdLS).

\section{Cornelia de Lange Syndrome (CdLS)} merupakan kelainan genetik yang muncul sejak lahir, tapi tidak selalu terdiagnosa saat lahir. Syndrome ini cenderung relatif tidak umum dan menyebabkan keterlambatan perkembangan dan kognitif yang mendominasi pada individu dengan Cornelia de Lange Syndrome $(C d L S)$ terutama keterlambatan bicara yang parah (foundation, 2012). Tidak ada perbedaan angka kejadian CdLS pada laki laki dan perempuan, dan dapat ditemukan di semua ras, dan latar belakang etnik Penatalaksanaan pasien dengan Cornelia de Lange Syndromr (CdLS) membutuhkan multidisiplin ilmu untuk mencapai hasil yang maksimum dan mencegah keterlambatan perkembangan umum bahkan kematian (Nugraha, 2015).

Ada dua fenotipe yang dapat dibedakan dari Cornelia de Lange Syndrome (CdLS) yakni
Cornelia de Lange Syndrome (CdLS) klasik dan Cornelia de Lange Syndrome (CdLS) yang lebih ringan. Cornelia de Lange Syndrome $(C d L S)$ klasik Tipe I) : Pasien memiliki perubahan wajah dan rangka sesuai gambaran dari kriteria diagnostik, mereka memiliki kekurangan pertumbuhan prenatal, keterlambatan psikomotor sedang sampai berat, dan mafformasi besar yang mengakibatkan ketidakmampuan yang berat atau kematian (Krantz, et al., 2004). Cornelia de Lange Syndrome (CdLS) yang lebih ringan : Tipe II, atau Cornelia de Lange Syndrome $(C d L S)$ ringan, pasien memiliki wajah yang mirip dengan tipe I, mereka memiliki keterlambatan psikomotor ringan sampai perbatasan, defisiensi pertumbuhan pra-dan postnatal kurang berat, dan tidak adanya (atau kurang beratnya) tingkat malformasi (John, Bhonsale, Shivashanker, \& Johns, 2012) (Tekin, 1993) (Braddock, et al., 1993). Tipe III atau fenokopi Cornelia de Lange Syndrome $(C d L S)$, termasuk pasien yang memiliki manifestasi fenotipik Cornelia de Lange Syndrome $(C d L S)$ yang penyebabnya berkaitan dengan perubahan kromosom atau paparan teratogen (O'Donnell, Davis, \& King, 1985) ( (Beck \& Fenger, 1985).

Ciri-ciri anak dengan Cornelia de Lange Syndrome $(C d L S)$ dilihat dari bentuk wajahnya adalah : alis mata yang menyatu di tengah, bulu mata yang panjang, hidung pendek dengan lubang hidung sedikit menengadah ke atas, jarak antara bibir atas dan hidung yang panjang, pangkal hidung luas atau datar, dagu kecil atau petak, bibir tipis dengan sudut menurun (downturn), celah langit langit mulut yang tinggi, gigi jarang atau gigi yang tidak tumbuh. Kriteria mayor dilihat dari pertumbuhannya (>2 kriteria) adalah BB/umur dibawah 5 persentil TB/umur dibawah 5 percentil dan Lingkar kepala disbanding umur dibawah 5 percentil, dilihat dari perkembangannya Developmental Delay (keterlambatan tumbuh kembang) atau gangguan intelektual dengan gangguan bahasa yang sangat terpengaruh daripada kemampuan motoric dan kesulitan belajar, dilihat dari perilakunya ( $>2$ kriteria) adalah Attention Deficit Disorder (ADD) ditambah hiperaktif, Karakteristik Obsessive-Compulsive, Anxietas 
(gelisah), selalu bergerak, agresif, perilaku menyakiti diri sendiri, menarik diri atau sangat pemalu, dan perilaku seperti Autis (foundation C. d., 2018)

Kriteria minor adalah dilihat dari muskuloskeletal (1 atau lebih dari kriteria) : tidak ada lengan bawah atau lengan atas, dijumpai 3 atau lebih dari penemuan di bawah ini atau tangan dan kaki yang kecil dan/atau tidak adanya beberapa jari dengan 2 atau lebih dari penemuan ini (Jari kelima yang bengkok, garis tangan abnormal, dilokasi siku /ekstensi abnormal pada siku, jempol yang lebih proksimal, Jari kaki kedua dan ketiga yang berhimpitan/menyatu, skoliosis, deformitas tulang dada atau rongga dada, dan dislokasi atau dysplasia panggul). Dilihat dari sensorineural/kulit : kelopak mata lemah (tampak mengantuk), malformasi mata berat, gangguan pendengaran, kejang, kulit seperti bercak bercak (mottled appearance), rambut tubuh yang banyak, putting susu kecil dan atau udel (pusar). Dilihat dari sistem-sistem yang lain (3 atau lebih) : malformasi/ malrotasi gastrointestinal, hernia diafragmatika, reflux gastrointestinal, langit mulut terbelah atau berselaput, CHD (Congenital Heart Disease), mikropenis, kelainan muara urethra, undescendus (testis tidak turun), dan malformasi saluran kemih (Clark, et al., 2012).

\section{Angka kejadian Cornelia de Lange Syndrome} (CdLS) diperkirakan 1:30.000 hingga 1:50.000 angka kelahiran hidup 9 Saat ini di Indonesia terdapat 30 penderita Cornelia de Lange Syndrome (CdLS) yang tersebar di seluruh profinsi, dan di Jawa Tengah terdapat 2 penderita Cornelia de Lange Syndrome (CdLS) yaitu di Yogyakarta dan di Semarang. Melihat fenomena yang terjadi maka penulis tertarik untuk melakukan study kasus tentang Gambaran Perkembangan Komunikasi An. B Dengan Cornelia De Lange Syndrome Di Poli Tumbuh Kembang Anak Rsup Dr. Kariadi Semarang

Tujuan dari penelitian ini adalah untuk melihat peningkatan perkembangan komunikasi anak Cornelia de Lange Syndrome (CdLS), setelah diberikan intervensi dengan menggunakan play terapi dan terapi wicara dengan menggunakan media gambar dan warna.

\section{METODE}

Penelitian ini menggunakan desain studi kasus. Kasus yang diambil sebanyak 1 kasus yaitu pada anak B (3 tahun, 9 bulan, 3 hari). Tempat diadakannya penelitian ini adalah di ruang Poli Tumbuh Kembang Anak RSUP DR. KARIADI SEMARANG. Penelitian ini dilakukan pada bulan November 2018. Sampel dalam penelitian ini adalah anak yang melakukan play terapi terapi wicara dengan kasus Cornelia de Lange Syndroma. Data didapatkan dengan cara pengkajian dengan melihat dari catatan medis dan keperawatan, observasi dan wawancara.

Untuk mengkaji komunikasi anak, peneliti menggunakan penilaian perkembangan dengan DDST II (Denver Development Screening Test II) (Frakenburg \& Dodds, 1967) dari sektor bahasa yang terdiri darai 39 item, yaitu bereaksi terhadap bel, bersuara, ooo/aah, tertawa, berteriak, menoleh ke bunyi icik-icik, menoleh ke arah suara, satu silabel, meniru bunyi kata-kata, papa/mama tidak spesifik, kombinasi silabel, mengoceh, papa/mama spesifik, 1 kata, 2 kata, 3 kata, 6 kata, menunjukkan 2 gambar, kombinasi kata, menyebut satu gambar, bagian badan 5, menunjuk 4 gambar, bicara dengan dimengerti, menyebut 4 gambar, mengetahui 2 kegiatan, mengerti 2 kata sifat, menyebut satu warna, kegunaan 2 benda, menghitung satu kubus, kegunaan 3 benda, mengetahui 4 kegiatan, bicara semua dimengerti, mengerti 4 kata depan, menyebut 4 warna, mengartikan 5 kata, mengetahui 3 kata sifat, menghitung 5 kubus, berlawanan 2 mengartikan 7 kata (Frakenburg \& Dodds, 1967).

Pada usia 3 tahun, 9 bulan ini perkembangan bahasa anak yang harus dilalui oleh anak adalah anak sudah mengerti 2 kata sifat, anak sudah mengetahui 2 macam kegiatan, anak sudah bisa menyebut 4 gambar, anak sudah bisa bicara dengan dimengerti, anak menunjuk 4 gambar, anak sudah bisa menyebutkan 
bagian-bagian dari badan, dan anak harus sudah bisa merangkai kata-kata menjadi sebuah kalimat, dan memiliki 6 suku kata sebagai perbendaharaan kata (Frakenburg \& Dodds, 1967).

Diagnosa keperawatan terkait dengan masalah komunikasi pada kasus ini adalah hambatan komunikasi verbal berhubungan dengan ketidakcukupan stimuli dan gangguan perkembangan dengan kode diagnosa 051 (Herdman \& Kamitsuru, 2017). Intervensi pada anak berdasarkan Nursing Outcomes Classification (NOC) adalah komunikasi yaitu penerimaan, interpretasi, ekspresi lisan, tertulis dan pesan non verbal dengan kode NOC 902, dengan skala outcome: menggunakan bahasa tertulis, menggunakan bahasa lisan, menggunakan foto dan gambar, menggunakan bahasa isyarat, menggunakan bahasa non verbal, mengenali pesan yang diterima, interpretasi akurat terhadap pesan yang diterima, mengarahkan pesan pada penerima yang tepat, dan pertukaran pesan yang akurat dengan orang lain.. ${ }^{16}$ Berdasarkan Nursing Interventions Classification (NIC), intervensi bisa dilakukan menggunakan peningkatan komunikasi : kurang bicara dengan kode NIC 4976 (Bulechek, Butcher, Dochterman, \& Wagners, 2013).

Untuk meningkatkan komunikasi kurang bicara pada anak, terapi bermain (Play therapi) dipilih sebagai salah satu aktifitas yang digunakan dengan bermain menggunakan symbol. Disini anak kita ajak untuk bermain peran, anak bisa menjadi apa saja yang diinginkan oleh anak misalnya menjadi binatang kucing atau kambing. Anak kita ajak untuk menirukan suara binatang yang di inginkan anak. Bermain peran disini juga bisa disesuaikan dengan kondisi situasi saat ini, misalnya anak berada di rumah sakit, anak bisa kita ajak bermain peran sebagai perawat dan dokter (Jateng, 2007).

Terapi wicara adalah terapi kolaborasi yang diberikan untuk anak dengan menggunakan gambar dan warna. Media kartu bergambar disini berisi simbol obyek, aktifitas, atau orang yang representatif (mewakili). Melalui kartu bergambar ini anak akan berusaha membayangkan secara mental obyek yang diinginkan (sesuai gambar) sehingga mereka belajar mengaitkan antara objek dengan gambar, kata dengan simbol gambar atau nama objek tersebut dengan penggunaan gambar atau simbol menjadi jembatan untuk nantinya berbicara menggunakan suara. Adanya bantuan gambar atau simbol juga membantu pemahaman anak akan bahasa yang disampaikan secara verbal (Cempaka, 2013).

\section{HASIL}

Berdasarkan hasil pengkajian tanggal 9 November 2018 didapatkan anak B berusia 3 tahun, 9 bulan, 3 hari dengan diagnosa medis Cornelia de Lange Syndrome dengan keluhan anak belum bisa bicara. Dari hasil pemeriksaaan fisik, bentuk wajah: alis mata menyatu ditengah, bulu mata panjang, hidung pendek dengan lubang hidung sedikit menengadah keatas, jarak antara bibir atas dan hidung panjang, pangkal hidung luas dan datar, sudut bibir menurun (downturn), gigi kecil-kecil dengan spektrum luas. Kriteria mayor: $\mathrm{BB}=10,2 \mathrm{~kg} ; \mathrm{TB}=84 \mathrm{~cm}$; Lingkar Kepala $=45 \mathrm{~cm}$; anak baru bisa mengucapkan 3 kata yaitu mamah, ayah, moh; anak tidak bisa fokus pada sebuah kegiatan, anak selalu bergerak; anak mudah gelisah, anak tidak mau bergaul dengan teman sepermainan. Kriteria Minor: kelopak mata lemah (tampak mengantuk); rambut tumbuh lebat.

Pada awal pemeriksaan ini telah dilakukan berbagai pemeriksaan penunjang dan kolaborasi dari berbagai disiplin ilmu. Dari hasil Echocardiografi (anak), struktur dan fungsi jantung dalam batas normal. Dari hasil pemeriksaan Bera telinga kanan gelombang $\mathrm{V}$ terdeteksi pada $20 \mathrm{~dB}$, telinga kiri gelombang $\mathrm{V}$ terdeteksi $20 \mathrm{~dB}$. Jadi ambang pendengaran masih dalam batas normal pada kedua telinga. Dari hasil pemeriksaan laboratorium Imunoserologi, TSHs 2,93 dan Free T4 15,84.

Hasil pemeriksaan DENVER II dari segi bahasa anak masih seperti anak berusia 18 bulan. Anak baru bisa mengucapakan 3 kata (mama, ayah, moh). Anak belum bisa 
menirukan bunyi kata-kata, kombinasi kata masih sedikit. Pada usia 3 tahun 9 bulan, anak seharusnya sudah bisa bicara 6 kata, merangkai kata-kata, menunjuk 4 gambar, menyebutkan bagian badan, mengetahui 2 kegiatan, mengerti 2 kata sifat, dan menyebut satu warna.

Berdasarkan hasil pengkajian tersebut, diagnosa yang muncul pada anak $\mathrm{B}$ adalah hambatan kominikasi verbal dengan kode NANDA 51 (Herdman \& Kamitsuru, 2017). Tujuan NOC dari diagnosa keperawatan ini adalah komunikasi anak menjadi baik dengan kode NOC 902 (Moorhead, Johnson, Maas, \& Swanson, 2013). Intervensi keperawatan yang diberikan yaitu peningkatan komunikasi kurang bicara dengan kode NIC 4976 (Bulechek, Butcher, Dochterman, \& Wagners, 2013). Disini kita menginstruksikan kepada klien dan keluarga untuk menggunakan proses kognitif, anatomis dan fisiologi yang terlibat dalam kemampuan berbicara dengan menggunakan play terapi. Untuk kegiatan kolaboratif bersama ahli terapis wicara, kami menggunakan media gambar dan warna untuk menstimulus perkembangan bahasa reseptif dan bahasa ekspresif.

Bagan 1 gambaran komunikasi anak setelah diberikan asuhan keperawatan selama 4 minggu dari tanggal 9 November 2018 samapi 3 desember 2018.

\begin{tabular}{lcccc}
\hline \multicolumn{1}{c}{ Skala outcome } & Minggu & Minggu & Minggu & \multicolumn{2}{c}{ Minggu } \\
& I & II & III & IV \\
\hline Menggunakan bahasa tertulis & 1 & 1 & 1 & 1 \\
\hline Menggunakan bahasa lisan & 1 & 2 & 2 & 3 \\
\hline Menggunakan foto dan gambar & 1 & 2 & 3 & 3 \\
\hline Menggunakan bahasa isyarat & 2 & 3 & 3 & 4 \\
\hline Menggunakan bahasa non verbal & 2 & 3 & 3 & 4 \\
\hline Mengenali pesan yang diterima & 1 & 2 & 3 & 3 \\
\hline Interpretasi akurat terhadap pesan yang diterima & 1 & 1 & 2 & 2 \\
\hline Mengarahkan pesan pada penerima yang tepat & 1 & 2 & 2 & 3 \\
\hline Pertukaran pesan yang tepat dengan orang lain & 1 & 1 & 2 & 2 \\
\hline Keterangan :
\end{tabular}

Keterangan : 1. Sangat terganggu; 2. Banyak terganggu; 3. Cukup terganggu; 4. Sedikit terganggu; 5. Tidak terganggu

\section{PEMBAHASAN}

Berdasarkan hasil pengkajian didapatkan diagnosa yang muncul yaitu hambatan komunikasi verbal. Tujuan intervensi dari diagnosa keperawatan ini adalah peningkatan komunikasi, dengan skala outcome: klien menggunakan bahasa tertulis, klien menggunakan bahasa lisan, klien menggunakan foto dan gambar, klien menggunakan bahasa isyarat, klien mampu menggunakan bahasa non verbal, klien mengenali pesan yang diterima, klien dapat menginterpretasikan keakuratan terhadap pesan yang diterima, klien mengarahkan pesan pada penerima yang tepat, dan klien dapat melakukan pertukaran pesan yang tepat dengan orang lain.
Intervensi yang dapat dilakukan pada diagnosa ini adalah peningkatan komunikasi kurang bicara, dengan aktifitas kita menginstruksikan kepada klien dan keluarga untuk menggunakan proses kognitif, anatomis dan fisiologi yang terlibat dalam kemampuan berbicara dengan menggunakan play terapi. Sesuai dengan karakter anak, maka anak kita ajak untuk bermain. Terapi bermain merupakan salah satu pendekatan bantuan penyembuhan bagi anak-anak berkebutuhan khusus. Seperti yang dikemukakan oleh landreth (1991); moustakas (1998); schaefer (1993), menyebutkan bermain sebagai bahasa simbolik anak yang alami untuk menyatakan emosi dan pengalaman sehari-hari, bahkan bermain adalah proses penyembuhan diri anak (Jateng, 2007). Zellawati juga mengemukakan 
dalam majalah ilmiahnya bahwa manfaat bermain adalah untuk perkembangan aspek fisik, perkembangan aspek motorik kasar dan halus, perkembangan sosial, perkembangan kognisi dan menjadikan anak kreatif dan bukan anak yang acuh tak acuh terhadap kejadian sekelilingnya (Alice, 2011).

Goodban juga mengemukakan dalam penelitiannya, bahwa untuk merawat anak dengan CdLS dimulai dengan aktifitas motorik kasar untuk memperkenalkan gagasan meniru dari permainan, kemudian memberikan pujian yang akan membentuk perilku yang positif. Setelah itu,suruh anakuntuk menirukan sebuah kata (Tanjung \& Panggabean, 2000). Hasil dari implementasi ini terjadi peningkatan dengan penggunaan bahasa non verbal dan bahasa isyarat. Pada penggunakaan bahasa tertulis tidak terjadi peningkatan dikarenakan anak belum bisa menulis dan membaca. Pada penggunaan bahasa lisan juga tidak mengalami peningkatan yang signifikan dikarenakan perbendaharaan kata anak masih sangat terbatas.

Anak dikatakan mampu berkomunikasi bila anak memperhatikan mitra bicara (Tanjung \& Panggabean, 2000). Untuk kegiatan kolaboratif bersama ahli terapis wicara, kami menggunakan latihan komunikasi dengan menggunakan media gambar dan warna untuk menstimulus perkembangan bahasa reseptif dan bahasa ekspresif anak. Bahasa reseptif adalah kemampuan untuk mengerti apa yang dilihat dan apa yang didengar dengan tujuan untuk membantu anak mengembangkan kemampuan mendengarkan, mengidentifikasi konsep melalui pemahaman pelabelan katakata, dan meningkatkan kemampuan merespon setiap komunikasi. Bahasa ekpresif adalah kemampuan untuk berkomunikasi secara simbolis baik visual ataupun auditorial dengan tujuan untuk membantu anak agar dapat mengekspresikan kebutuhannya, keinginannya, dan perasaannya secara verbal (Fatwikiningsih, 2014). Pada anak B, setelah dilakukan intervensi kolaboratif ini, terjadi peningkatan pada komunikasi anak. Hal ini sesuai dengan penelitian Fatwikiningsih, yang menunjukan terdapat perbedaan signifikan kemampuan bahasa reseptif dan ekspresif terhadap anak yang diberikan intervensi dan yang tidak diberikan kontrol intervensi (Fatwikiningsih, 2014).

\section{SIMPULAN}

Berdasarkan hasil evaluasi setelah 1 bulan dilakukan tindakan keperawatan dan kolaborasi dengan terapist wicara, telah terjadi peningkatan pada komunikasi anak dengan Cornelia de Lange Sindrome (CdLS), ibu mengatakan anaknya sudah mulai bisa mengungkapkan keinginan secar non verbal, dan anak sudah mulai bisa menunjukkan bagian-bagian tubuhnya. Ibu klien juga mengatakan anaknya sudah mulai mau bermain dan berbagi mainan dengan teman sepermainannya. Untuk mengungkapkan keinginannya, anak sudah bisa mengungkapkan dengan bahasa isyarat, yaitu menunjuk dengan tangannya.

Berdasarkan studi kasus yang telah dilakukan, maka saran yang dapat disampaikan bagi peneliti selanjutnya yaitu diharapkan dapat melakukan studi kasus lain terkait peningkatan bahasa anak dengan Cornelia de Lange Sindrome. Bagi orang tua anak dengan Cornelia de Lange Sindrome (CdLS) diharapakan dapat memberikan stimulus yang lebih banyak kepada anak di rumah.

\section{REFERENSI}

Alice, Z. (2011). Terapi bermain untuk mengatasi permasalahan pada anak . Majalah ilmiah informatika, 2(3); 164-175. 
Bahri, S. (2010). Guru dan anak didik dalam interaksi edukatif suatu pendekatan teoritis psikologis. Jakarta: Rineka Cipta.

Beck, B., \& Fenger, K. (1985). Mortalit, pathological findings and causes of death in the de large syndrome. Acta Paediatr Scand, 74;765-769.

Braddock, S., Lachman, R., Stoppenbagen, C., Carey, J., Ireland, M., \& Moeschler, J. (1993). Radiological features in brachmann de lange syndrome. Am J Med Genet A, 47; 1006-1013.

Bulechek, G., Butcher, H., Dochterman, J., \& Wagners, C. (2013). Nursing interventions classification (NIC) edisi keenam bahasa Indonesia. Oxford: Elsevier.

Cempaka, A. (2013). Penerapan media story pictures dalam pembelajaran membaca. Universitas pendidikan indonesia, 13.

Clark, D., Sherer, L., Deardoff, M., Byne, J., Loomes, K., \& Nowaczyk, M. (2012). Prenatal profile of cornellia de large syndrome: a review of 53 pregnancies. Am j Med Genet A, 158(8);1848-1856. Fatwikiningsih, N. (2014). Peningkatan kemampuan berbahasa melalui metode berkomunikasi dengan gambar pada anak dengan ciri gangguan pemusatan perhatian dan hiperaktivitas. Jurnal
SAINS dan Praktik Psikologi, 2(3):226-242.

foundation, C. d. (2012, Februari 24 ). Diagnostic criteria checklish for cornelia de lange syndrome. Retrieved from 4. Cornelia de Lange Syndrome Foundation. 2010.Diagnostic Criteria Checklist for Cornelia de Lange Synhttp://www.cdlsusa.org/profession al-education/diagnostic checklist.htm. foundation, C. d. (2018, November 18). Treatment protocol. Retrieved from USA:Cdls Foundation: http://www.cdlsusa.org/what-iscdls/treatment-protocols.htm

Frakenburg, W., \& Dodds, J. (1967). The denver development screening test. The Journal of pediatrics, 7(2);181191.

Herdman, T., \& Kamitsuru. (2017). NANDA-I Diagnosis keperawatan definisi dan klasifikasi 2018-2020. Jakarta: EGC.

Jateng, D. P. (2007). Bermain peran panduan praktis pendidi PAUD. Semarang. John, D., Bhonsale, D., Shivashanker, V., \& Johns, M. (2012). Aesthetic and fungsional management of a patient with cornelia de large syndrome. COntemp clin dent, 86-91.

Krantz, I., McCallum, J., DeScipio, C., Kaur, M., Gillis, L., \& Yaeger, D. (2004). Cornelia de Lange syndrome is caused by mutations in NIPBL, the human 
homolog of drosophilamelanogaster. Nature Genet, 631-635.

Maryanti, D., \& Kusumawati, D. (2015). Faktor-faktor risiko terjadinya kelainan kongenital. Jurnal Kesehatan Al Irsyad, 7(1).

Moorhead, S., Johnson, M., Maas, M., \& Swanson, E. (2013). Nursing

Ourcomes Classification (NOC) edisi kelima bahasa Indonesia. Oxford: Elsevier.

Nugraha, A. (2015). A Cornelia de lang syndrome with sepsis neonatorum and respiratory distress syndrome.$J$ Agromed Unila, 2(1).
O'Donnell, D., Davis, P., \& King, N. (1985). Management problems associated with cornelia de large syndrome. Spec Care Dentist, 5:160-163.

Soetiningsih. (2016). Tumbuh kembang anak. Jakarta: EGC.

Tanjung, N., \& Panggabean, E. (2000). Kiat meningkatkan spontanitas penyandang autisme dalam berkomunikasi. Jakarta: Yayasan Autisma Indonesia.

Tekin, M. (1993). Cornelia de large syndrome: differential diagnoses \& worup (typus amtelodamensis. Arch Med Enfants, 36; 713-719. 